\title{
Can Social Support and Control Agency Change Illness Consequences? Evidence from Cervix Cancer Patients
}

\author{
Purnima Awasthi*, Ramesh C. Mishra \\ Department of Psychology, Banaras Hindu University, Varanas, India \\ Email: *awasthip9@gmail.com
}

Received April 29, 2013; revised May 31, 2013; accepted June 10, 2013

Copyright (C) 2013 Purnima Awasthi, Ramesh C. Mishra. This is an open access article distributed under the Creative Commons Attribution License, which permits unrestricted use, distribution, and reproduction in any medium, provided the original work is properly cited.

\begin{abstract}
Research has demonstrated facilitative effects of social support on psychological and physical well-being of individuals suffering from chronic health problems. Social support can change not only patients' perception of their health problems, but also the consequences of their illness. In the present study with cervix cancer patients, the relationship of social support and illness control agency with illness consequences and health outcome beliefs was examined. Emotional, informational, social companionship and practical supports were found to be negatively correlated with the severity of interpersonal, physiological and psychological consequences of illness. Patients' belief in self-control and doctor-control was related to less severity and less pain of illness, and strong hope for better health outcomes.
\end{abstract}

Keywords: Cervix Cancer; Health Beliefs; Social Support; Control Agency

\section{Introduction}

An important development to take place in medical sciences during the last decades is the recognition of psychological factors in the origin, development, treatment and management of physical health problems. Improvement in people's quality of life is another important concern, especially in the case of chronic health problems, which pose serious threat to human life. Chronic diseases, such as diabetes, cancer, arthritis, asthma, tuberculosis and heart attack, are a major cause of morbidity in many developing countries, including India [1]. Cancer is one of the ten leading causes of death in India. It is estimated that there are approximately 2.5 million cancer cases at any given point of time; that about 300 thousand deaths occur annually due to cancer; and that oral and lung cancers in males, and cervix and breast cancers in females, account for over 50 percent of all cancer-related deaths in India $[2,3]$.

\subsection{Health Beliefs and Behavior}

Human beings are embedded in a socio-cultural context within which they acquire knowledge about health and health problems. They learn not only the name of diseases (e.g., fever, cholera), but also their symptoms, aeti-

"Corresponding author. ology and ways of prevention and treatment. A variety of beliefs about causes, controllability and outcomes of different diseases prevail in societies. As an integral part of the cognitive system [4], and also possibly of the neural system [5], beliefs determine not only health cognition, but also treatment strategies, perceived treatment outcomes and coping strategies of individuals. Health intervention programs often aim at changing faulty beliefs and attitudes widely held by individuals of particular social or cultural groups [6].

Research $[7,8]$ indicates that patients' own beliefs and understanding of health and treatment regulate their health behaviour. People not only seek medical explanations of their disease, but also try to understand the disease within their social and cultural context [9]. A common sense understanding of causes of illness is often a social construction derived from the cultural models of illness [10]. Family members, friends, social networks, and medical practitioners play crucial role in the formation of health beliefs and behaviours.

It has been observed [11] that when people suffer from a chronic illness, their self-perception gets blurred. To regain self-sensibility, they try to make sense of the illness by extending their formulations about illness beyond medical explanations to embrace social-psychological implications for themselves and their family. Research in India [12] reveals that people often seek help of their 
close relatives and friends to arrive at a naïve diagnosis and explanation of health problems. Such behaviours in relation to health have been reported in other studies as well [13]. In explaining health problems, people attribute causality either to themselves (e.g., careless attitude, bad habits) or to external factors (e.g., environmental hazards, god's wish). In Indian studies, a coexistence of both set of factors has been reported [14]. In view of these evidences and in terms of attribution theory [15], it may be argued that in the Indian cultural context in which concepts of gods, goddesses, spirits, and fate are transmitted to children as indispensable lessons, individuals are likely to consider external factors to be responsible for health problems more than individual factors. The attribution of causality to external factors is likely to lead to a strong belief in external agency for the control of illness.

\subsection{Social Support, Control Agency and Illness Consequences}

Much of the research with women suffering from chronic diseases shows that they pass through a phase of significant life change during which they need immense psychological and social supports to cope with the challenges of disease. Studies with patients of heart surgery [16], stroke [17], coronary heart disease [18], cancer [19] and dialyses [20] indicate strong association between social support and improved psychological adjustment.

In studies of the effect of social support, the characteristics of social network and functional aspects of interactions between members are considered important. Social relationships are formed by people who provide emotional support, companionship, instrumental help, and advice [21] and serve as a resource in difficult situations. Some research indicates that social well-being is directly influenced by the number of resources that a person possesses [22]. Wellbeing is considered as a product of the interrelationship of physical, psychological and social factors [23]. Thus, social support works as a resource that resounds in social wellbeing, health, overall quality of life and longevity of patients [24]. Multi-componential models of psychological health [25] explain the impact of social support on wellbeing in terms of cognitive, behavioural and emotional mechanisms.

Considerable individual differences have been reported in people's ability to utilize social support $[26,27]$. Significant interactions have been found between negative life events and social support in predicting psychological distress for individuals who attribute negative life circumstances to internal factors, but not with individuals who attribute them to external factors. The relationship between internal control beliefs and perception of social support has been a matter of research for quite some time. Studies [28-30] reveal that internal attribution style, internal control beliefs and their association with percep- tion of social support are important psychological factors influencing the well-being of patients and their compliance with treatment regimens.

Perceived support has also been considered as a part of individuals' personality and it has been argued that the same level of support may generate different perception of support availability in different individuals [31]. Research indicates greater effect of perceived social support on individuals' psychological well-being than the actual amount of support one has been provided with [32]. Nevertheless, depending on the nature of personality, the satisfaction people derive from the available social support might be more critical than the perceived availability of social support.

Relationship between illness cognition, coping, and adjustment has been examined in patients characterized by chronic fatigue syndrome [33]. Illness perceptions were found to explain greater percent of the variation in the level of individuals' psychological well-being than the coping strategy used to manage illness. Findings also indicated that positive interpretation of health problems and social support were positively related to internal control and self-oriented health beliefs.

Findings about beliefs in internal and external control agencies and their relationship with social support as reported above, however, have not always been borne out in studies. While patients with internal control beliefs have been found to perceive social support to a greater extent than those with external control beliefs, there is evidence for strong relationship between social support and psychological wellbeing even for patients with external control beliefs [30].

Research has revealed that when encountering negative life events, social support buffers the development of mental disorder [34]. This outcome, however, is observed only for patients with external control beliefs, while those with internal control beliefs do not have the same need to cope with negative events. Even depression has been found to be highest among people having external control beliefs who perceive little support [35]. The strong association between social support and psychological wellbeing generally found for patients with external control beliefs more than those with internal control beliefs goes against the findings reported earlier for the internal control beliefs.

Studies with orthopedic [36], tubercular [37] and heart [38] patients reveal that God's will and karma are frequently attributed as causes of diseases by Hindu patients. These studies place emphasis on cultural and social contexts in understanding and dealing with health problems. That individuals' culturally determined systems of belief about health and illness have major influences on their health behaviour and practices is reported in other studies [39]. Studies carried out with women patients suffering 
from cancer [40] and diabetes [41] broadly suggest the coexistence of internal (individual, psychosocial) and external (supernatural, environmental) causes of illness in the belief system of patients. The findings of these studies also suggest that social support tends to reduce not only the severity of negative consequences of illness, but also the experience of disease-related pain. The role of social support and control agency in cancer-related sufferings, however, needs to be analysed in relation to patients' belief about illness consequences (e.g., physical, psychological and interpersonal functioning) and illness outcomes (e.g., pain, severity of illness, and hope for cure).

The present study, carried out with cervix cancer patients, attempts to examine the relationship of social support and control agency in perceived illness consequences and future outcomes of illness. Focus on cervix cancer in the study is because of the identification of cervix cancer as one of the leading causes of death among Indian women. Population-based cancer registries (PBCRs) of India indicates its incidence in two out of the 12 cases. As compared to all other types of cancer, the age-adjusted incidence of cervical cancer (30.7 per 100,000 women, 132,082 incident cases) is found to be the highest in India and also higher than the average for the South Central Asian region. By 2025 the number of new cervical cancer cases in India is projected to increase to 226,084 [3]. Guided by this picture, the present study attempts to analyse some psychological aspects of cervix cancer patients. In the light of general findings reported in this area, it was hypothesized that:

1) Social support would be negatively correlated with pain and severity of illness, whereas it would be positively correlated with hope for better outcomes of illness.

2) Belief in the control agency of "self" and "doctor" would be associated with lesser severe consequences of illness as compared to belief in "supernatural" control agency.

\section{Method}

\subsection{Participants}

The study was carried out with 100 women patients suffering from cervix cancer. The patients were drawn from the out patient departments (OPD) of medical centres and hospitals located in Varanasi city. The inclusion criteria for participants were: 1) their age was between 30 and 65 years, 2) their cancer was of second or third stage, 3) they were not hospitalized, 4) they belonged to middle and upper middle socio-economic status, and 5) they came from joint families. The exclusion criteria were: 6 ) less than 30 and more than 65 years of age, 7) first and fourth stage of cancer, 8) hospitalization, 9) low or high socio-economic status, 10) nuclear family status, and 11) evidence of psychiatric illness.

\subsection{Measures}

The following measures were used in the study; psychometric properties and other details of the measures can be found elsewhere [40].

\subsubsection{Illness Consequences Belief Measure}

It comprised 15 items related to physiological, psychological, and interpersonal consequences of disease. The participants were asked to rate each item on a 5-point scale for its consequence ("very much" $=5$, "very little" $=1$ ). The score range on each consequence measure was 5 to 25 .

\subsubsection{Illness Controllability Belief Measure}

It consisted of 3 items that assessed the degree to which the participant believed that the disease was controllable by "self", "external agents" or a "doctor". Each item was rated on a 5-point scale, ranging from "not at all" (1) to "very much" (5).

\subsubsection{Illness Outcome Belief Measure}

This measure of 3 items assessed the outcomes of illness in terms of the subject's pain (how much painful do you find your illness to be), hope (how much do you hope that your illness will be cured), and severity (how much severe do you think your illness is) of illness. Each item was rated on a 5-point scale ranging from "not at all" (1) to "very much" (5). Test-retest reliabilities of items of this measure were $0.87,0.91$ and 0.92 respectively.

\subsubsection{Social Support Measure}

This measure [42] assesses emotional (15 items), informational (6 items), social companionship (6 items), and practical (11 items) supports. Four types of responses are sought: 1) who gives you this support, 2) from whom do you expect this kind of support, 3) how much support do you expect, and 4) how much support do you get? For questions "c" and "d", a 7-point scale is used. This paper uses data obtained under "d" category (i.e., the degree of support patients received).

\section{Results}

\subsection{Social Support, Illness Controllability, Consequences, and Outcome Beliefs}

Means and standard deviations on different measures employed in the study are given in Table 1. With respect to social support, mean scores are generally higher for emotional and practical than for informational and social companionship supports. On the Illness Consequences measure, the mean scores are generally higher for interpersonal and psychological consequences than for phy- 
Table 1. Mean scores of women patients' on various measures of social support and illness beliefs.

\begin{tabular}{lcc}
\hline Social Support & Mean & Standard Deviation \\
\hline Emotional & 56.410 & 19.09 \\
Informational & 21.660 & 8.60 \\
Social Companionship & 23.550 & 8.86 \\
Practical & 45.640 & 14.62 \\
Overall & 2.0700 & 0.62 \\
Illness Consequences Belief & & \\
Interpersonal & 17.540 & 4.90 \\
Physiological & 15.600 & 4.05 \\
Psychological & 17.620 & 5.28 \\
Illness Controllability Belief & & \\
Self & 1.36 & 0.79 \\
Doctor & 3.78 & 1.09 \\
Supernatural & 1.55 & 1.12 \\
Illness Outcome Belief & & \\
Pain & 3.97 & 1.02 \\
Hope & 2.81 & 1.38 \\
Severity & 4.57 & 0.71 \\
\hline
\end{tabular}

siological consequences. On the Illness Controllability measure, the mean scores are higher for "doctor-control" and "supernatural-control" than for "self-control". On the Illness Outcome measure, the mean scores are generally higher for "severity" and "pain" than for "hope".

\subsection{Relationship of Social Support and Illness Control Agency with Other Measures}

Table 2 presents the values of correlation of social support and illness control agency with illness consequences and illness outcome measures. The scores of emotional, informational, social companionship and practical support measures show a negative relationship with interpersonal, physiological, and psychological consequences as well as with pain and severity of illness, but a positive relationship with hope. These results reveal that with social support there is less experience of interpersonal, physiological and psychological consequences, less feeling of pain and severity of illness, and strong hope for better outcomes. Belief in "self-control" was negatively correlated with psychological consequences and positively with hope, indicating that with belief in "self-control" negative psychological consequences of disease are experienced less, and the hope is enhanced. Belief in "doctor-control" shows a negative relationship with interpersonal, physiological, and psychological consequences as well as with pain and severity of illness, but a positive relationship with hope, suggesting that with strong belief in "doctor-control" negative interpersonal, psychological, and physiological consequences as well as pain and severity of illness are experienced less, and the hope for better outcomes is enhanced. "Supernatural control" was positively correlated with interpersonal, physiological, and psychological consequences, and pain measures showing that with belief in "supernatural control" women experience severe consequences of cancer including the pain.

\subsection{Multiple Regression Analysis}

Since it was not possible to establish any theoretical hierarchy of variables in terms of their effects, a step-wise Multiple Regression Analysis (Table 3) was carried out using social support and illness controllability as predictor variables, and illness consequences and illness outcomes as the criterion variables.

Findings revealed that practical support, doctor-control and supernatural control accounted for approximately 49 per cent of variance in the scores on interpersonal consequences measure $(\mathrm{F} 3,96,30.92, \mathrm{p}<0.01)$. "Doctorcontrol" $(\mathrm{b}=-0.30)$ and "practical support" $(\mathrm{b}=-0.52)$ made negative predictions (less serious consequences). The highest contribution was made by "practical support", which accounted for approximately 40 per cent of variance $(\mathrm{F} 1,98,65.14, \mathrm{p}<0.01)$ in the scores. "Doctorcontrol" and "supernatural control" accounted for approximately 7 percent and 3 percent of variance in the scores respectively.

Informational support, supernatural control and doctor control accounted for approximately 46 percent of the variance in scores on physiological consequences measure $(\mathrm{F} 3,96,4.93, \mathrm{p}<0.05)$. "Informational support" contributed approximately 32 percent $(\mathrm{F} 1,98,45.82, \mathrm{p}<$ $0.01)$, "supernatural control" contributed approximately 11 percent, and "doctor-control" contributed approximately 3 percent to variances in the scores on the physiological consequences measure. While informational support $(b=-0.49)$ and doctor-control $(-0.18)$ made negative predictions (less serious consequences); the prediction made by supernatural control $(b=0.29)$ was in the positive direction (serious consequences).

With respect to the prediction of psychological consequences, results indicated that overall support $(b=-0.44)$ and doctor-control $(b=-0.27)$ explained approximately 39 percent of variance in the scores $(F 2,97,30.35, p<$ 0.01 ). "Overall support" contributed approximately 34 per cent to variance in the scores $(\mathrm{F} 1,98,49.56, \mathrm{p}<0.01)$ and "doctor-control" accounted for approximately 5 per cent of variance in the scores. Overall support and doctor control emerged as negative predictors of psychological consequences (less serious consequences).

"Doctor-control" $(b=-0.30)$ accounted for approximately 21 percent of variance in the scores on pain measure $(\mathrm{F} 1,98,3.28, \mathrm{p}<0.05)$ and made negative predictions (less feeling of pain).

On the hope measure "doctor-control", "self-control", 
Table 2. Intercorrelation of scores on social support, illness control, consequences and outcome belief measures.

\begin{tabular}{|c|c|c|c|c|c|c|}
\hline & \multicolumn{3}{|c|}{ Illness Consequences Belief } & \multicolumn{3}{|c|}{ Illness Outcome Belief } \\
\hline & Interpersonal & Physiological & Psychological & Pain & Hope & Severity \\
\hline Emotional & $-0.54^{* *}$ & $-0.52^{* *}$ & $-0.56^{* *}$ & $-0.29^{* *}$ & $0.37^{* *}$ & -0.13 \\
\hline Informational & $-0.55^{* *}$ & $-0.56^{* *}$ & $-0.55^{* *}$ & $-0.33^{* *}$ & $0.45^{* *}$ & $-0.22^{* *}$ \\
\hline Social companionship & $-0.48^{* *}$ & $-0.44^{* *}$ & $-0.49^{* *}$ & $-0.27^{* *}$ & $0.34^{* *}$ & -0.10 \\
\hline Practical & $-0.63^{* *}$ & $-0.52^{* *}$ & $-0.55^{* *}$ & $-0.31^{* *}$ & $0.40^{* *}$ & -0.08 \\
\hline Overall & $-0.61^{* *}$ & $-0.52^{* *}$ & $-0.58^{* *}$ & $-0.28^{*}$ & $0.45^{* *}$ & -0.11 \\
\hline Self-Control & -0.22 & -0.06 & $-0.24^{* *}$ & -0.11 & $0.43^{* *}$ & -0.10 \\
\hline Doctor's Control & $-0.44^{* *}$ & $-0.32^{* *}$ & $-0.39^{* *}$ & $-0.31^{* *}$ & $0.61^{* *}$ & $-0.24^{* *}$ \\
\hline Supernatural Control & $0.20^{*}$ & $0.38^{* *}$ & 0.19 & $0.23^{*}$ & 0.5 & -0.04 \\
\hline
\end{tabular}

${ }^{*} \mathrm{p} \leq 0.05,{ }^{* *} \mathrm{p} \leq 0.01$.

Table 3. Summary of stepwise MRA.

\begin{tabular}{|c|c|c|c|c|c|c|c|}
\hline S.No. & $\begin{array}{l}\text { Predictor } \\
\text { Variables }\end{array}$ & $\begin{array}{c}\text { Multiple } \\
\text { R }\end{array}$ & $\mathbf{R}^{2}$ & $\mathbf{R}^{2}$ adj. & df & F Ratio & Beta \\
\hline \multicolumn{8}{|c|}{ Interpersonal Consequences } \\
\hline 1 & $\begin{array}{l}\text { Practical } \\
\text { Support }\end{array}$ & 0.632 & 0.399 & 0.393 & 1.98 & $65.14^{* *}$ & -0.52 \\
\hline 2 & $\begin{array}{l}\text { Doctor's } \\
\text { Control }\end{array}$ & 0.684 & 0.468 & 0.458 & 2.97 & $42.75^{* *}$ & -0.30 \\
\hline 3 & $\begin{array}{l}\text { Supernatural } \\
\text { Control }\end{array}$ & 0.701 & 0.491 & 0.476 & 3.96 & $30.92^{* *}$ & 0.16 \\
\hline \multicolumn{8}{|c|}{ Physiological Consequences } \\
\hline 1 & $\begin{array}{l}\text { Informational } \\
\text { Support }\end{array}$ & 0.564 & 0.319 & 0.312 & 1.98 & $45.82^{* *}$ & -0.49 \\
\hline 2 & $\begin{array}{c}\text { Supernatural } \\
\text { Control }\end{array}$ & 0.655 & 0.429 & 0.417 & 2.97 & $36.44^{* *}$ & 0.29 \\
\hline 3 & $\begin{array}{l}\text { Doctor's } \\
\text { Control }\end{array}$ & 0.676 & 0.457 & $0-440$ & 3.96 & $4.93^{*}$ & -0.18 \\
\hline \multicolumn{8}{|c|}{ Psychological Consequences } \\
\hline 1 & $\begin{array}{l}\text { Overall } \\
\text { Support }\end{array}$ & 0.580 & 0.336 & 0.329 & 1.98 & $49.56^{* *}$ & -0.44 \\
\hline 2 & $\begin{array}{l}\text { Doctor's } \\
\text { Control }\end{array}$ & 0.620 & 0.385 & 0.372 & 2.97 & $30.35^{* *}$ & -0.27 \\
\hline \multicolumn{8}{|c|}{ Pain } \\
\hline 1 & $\begin{array}{l}\text { Doctor's } \\
\text { Control }\end{array}$ & 0.461 & 0.212 & 0.189 & 1.98 & $3.28^{*}$ & -0.30 \\
\hline \multicolumn{8}{|c|}{ Hope } \\
\hline 1 & $\begin{array}{l}\text { Doctor's } \\
\text { Control }\end{array}$ & 0.611 & 0.374 & 0.367 & 1.98 & $58.45^{* *}$ & 0.44 \\
\hline 2 & Self-Control & 0.668 & 0.447 & 0.435 & 2.97 & $39.16^{* *}$ & 0.28 \\
\hline 3 & $\begin{array}{l}\text { Overall } \\
\text { Support }\end{array}$ & 0.073 & 0.494 & 0.478 & 3.96 & $31.20^{* *}$ & 0.24 \\
\hline \multicolumn{8}{|c|}{ Severity } \\
\hline 1 & $\begin{array}{l}\text { Doctor's } \\
\text { Control }\end{array}$ & 0.238 & 0.057 & 0.45 & 1.98 & $5.88^{*}$ & -0.24 \\
\hline
\end{tabular}

${ }^{*} \mathrm{p} \leq 0.05,{ }^{* *} \mathrm{p} \leq 0.01$.

and "overall support" accounted for approximately 49 per cent of the variance in scores $(\mathrm{F} 3,96,31.20, \mathrm{p}<$ 0.01). "Doctor-control" contributed approximately $37 \mathrm{per}$ cent ( $\mathrm{F} 1,98,58.45, \mathrm{p}<0.01)$, "self-control" contributed approximately 8 percent, and "overall support" contributed approximately 5 percent to variance in the scores on hope measure. Doctor-control $(b=0.44)$, self-control ( $b$ $=0.28)$ and overall support $(b=0.24)$ made positive predictions (greater hope for cure). On severity measure, "doctor-control" $(-0.24)$ emerged as a negative predictor (less severity of disease) and accounted for approximately 6 per cent of the variance in scores $(\mathrm{F} 1,98,5.88, \mathrm{p}<$ $0.05)$.

\section{Discussion}

The findings revealed "social support" and "doctor-control" to be associated not only with less severe illness consequences, but also with less experience of pain, less severity of illness outcomes and strong hope for cure of the disease. The hypothesis, that social support would be negatively associated with perceived consequences, pain and severity of illness, and positively with hope for better outcomes of illness, was strongly supported by the findings. All components of social support (i.e., emotional, informational, social companionship and practical) had negative relationship with interpersonal, physiological, and psychological consequences as well as with pain and severity of cancer, and a positive relationship with hope. These results are consonant with studies, carried out with other kind of patients, in indicating that people with strong social support psychologically adjust better to stressful events, and that perceived availability of social support has a positive effect on physical and psychological well-being $[12,43,44]$.

In health research, supportive social relationships have been conceptualized as operating in three possible ways to alleviate the problem of stress: 1) social support may enhance health by fulfilling many human needs such as affection, approval, social contact and security, 2) social support may reduce interpersonal tensions and enhance positive effects in the environment, and 3) social support may buffer an individual's exposure to stress resulting from the anticipation or experience of the chronicity of disease. Types and sources of social support have been shown to produce emotionally induced effects even on 
the neuroendocrine or immune system function [45]. Whether the mechanism is psychological or neural, the role of social support in adjustment to cancer is beyond doubt $[46,47]$. In comparative research on support functions [48], emotional support is typically shown to be related to adjustment, while instrumental support is sometimes indicated as a non-significant effect. In a meta-analysis of psychosocial variables related to breast cancer, significant effect sizes have been found for the association between development of breast cancer and reported stressful life events [49]. Support from health care professionals, family members and friends in such stressful situations may provide patients with psychological strength for dealing with negative consequences of disease (e.g., fears and anxieties, etc.) and developing an optimistic outlook concerning the cure of cancer.

The hypothesis, that belief in the control agency of "self" and "doctor" would be associated with lesser severe consequences of illness as compared to belief in "supernatural" control agency, was partially supported by the findings. Patients who believed in "self-control" and "doctor-control" also believed that the interpersonal, physiological, and psychological consequences of illness would be less severe. This was evidenced by negative correlations of self- and doctor-control with all types of illness consequences (see Table 2). Patients who believed in "self-control" and "doctor-control" felt that the outcome of illness would not only be less painful and less severe, but also their disease would be cured. Thus, while patients own efforts are important, doctors' sensitivity for and willingness to help can generate strong hope in patients to overpower their disease.

In recent years communication between patients and doctors about health issues has greatly improved. More patients now ask for "human side" of their care, and most of the doctors also now realize this aspect. Social cognition theory [50] suggests that patients' belief in "doctor-control" on illness is strongly influenced by their interpretation of this interactive relationship. When the interaction involves interpersonal relationships, patients make positive emotional responses, which lead to positive evaluations of the encounter and reduced severity of the health problem.

That "self-control" was related to less severity of psychological consequences of illness and enhanced hope for better health outcomes is another important finding of the study. Role of self-control beliefs in encouraging constructive reactions to serious illnesses has been shown in many early studies [51,52]. It is argued that individuals, who believe that their health and illness are under their own control, are more likely to engage in health promoting activities than those who believe that it is under the control of other factors [53]. Thus, patients, who believe that they have control over their illness, are better adjusted to illness than those who do not believe that way [54,55]. While control beliefs have sometimes been accused of generating "illusions of control", they still have positive consequences for patients in terms of facilitating psychological adaptation, and hence termed as "healthy illusions" [56].

The finding regarding "hope" documents the importance of "doctor-control" and "self-control" and perceived support in promoting optimism. Studies show that optimistic people generally believe in positive outcomes and are more problem-focused in their behaviour [57]. Optimistic people also tend to see problems as manageable rather than disastrous. Research has brought out positive role of hope in pain management in arthritis [58], fibromyalgia [59,60], and car accident injuries [61]. University students characterized by high hope have been found to show higher pain thresholds, higher pain tolerance, and lower pain severity on a cold pressure task [62]. This suggests that hope has a generalized beneficial effect on the experience of pain.

Belief in supernatural control agency had positive relationships with interpersonal, physiological and psychological consequences, showing severe consequences of cancer with "supernatural" orientation. This finding can be interpreted in terms of the Hindu worldview that emphasizes on "karma" for which support can be derived from theoretical writings [63] and empirical studies [36-38,64,65]. The karma theory holds that all good or bad deeds accumulate over our previous births, that the present sufferings are the outcome of the bad deeds of our previous births (not only of the present life), and that one must undergo suffering to get relieved from the effects of bad deeds. Search for explanation of sufferings seem to be the cornerstone of Indian philosophical traditions [66], and attribution of suffering to factors beyond oneself is a common aspect of the Indian mind set [67].

The study brings out the significance of social support and control orientations in psychological well-being of cervix cancer patients. Inadequate social support is likely to result in poor health outcome. The findings suggest that besides medical interventions, cervix cancer patients need to be provided with adequate social support. Mere feeling that they are supported by others can mitigate the negative consequences of illness, and enable them to meet the challenges of day-to-day problems. Findings related to "self-control" of illness can be useful for enhancing the feeling of "self-efficacy" among cancer patients. The finding indicating "doctor-control" on illness has implications for community health care activities.

In spite of the fact that the study has explored important psychological dimensions pertaining to women patients suffering from cervix cancer, there are also some limitations. First of all, the study was carried out with patients of a widespread age range (e.g., 30 to 65 years), 
but we have not used age as a factor in the present analyses. For developing age specific psychological profile, age-specific analyses and comparisons are warranted. The role of rural-urban residence and other contextual variables also need to be examined seriously. A comparative study of females and males suffering from other kinds of cancer may provide some further insights in this respect. Other limitations include lack of comparison of early and late stage cancer patients, ignoring the effect of hospitalization on patients' beliefs, not paying attention to socio-economic factors and nuclear family status in understanding the psychological processes addressed in the present study.

\section{REFERENCES}

[1] World Health Organization, "Women of South-East Asia: A Health Profile," Regional Publications, New Delhi, 2000 .

[2] National Cancer Registry Programme, "An Overview (19812001)," ICMR, New Delhi, 2002.

[3] World Health Organisation, "The Global Burden of Disease: 2004 Update,” WHO, Geneva, 2009.

[4] D. T. Gilbert, "How Mental System Believe," American Psychologist, Vol. 46, No. 2, 1991, pp. 107-109. doi:10.1037/0003-066X.46.2.107

[5] P. N. Tandon, "Belief: A Scientific Perspective," In: P. N. Tondon, R. C. Tripathi and N. Srinivasan, Eds., Expanding Horizons of the Mind Science(s), Nova Science Publishers, New York, 2011, pp. 235-247.

[6] M. Rodgers, D. Fayter, G. Richardson, G. Ritchie, R. Lewin and A. J. Sowden, "The Effects of Psychosocial Interventions in Cancer and Heart Disease: A Review of Systematic Reviews," Centre for Reviews and Dissemination (CRD), University of York, York, 2005.

[7] N. Roberts, E. Smith, S. Bennett, J. Cape, R. Norton and P. Kilburn, "Health Beliefs and Rehabilitation after Lumber Disc Surgery," Journal of Psychosomatic Research, Vol. 28, No. 2, 1984, pp. 139-144. doi:10.1016/0022-3999(84)90007-2

[8] L. M. Vaughn, F. Jacquez, R. C. Bakers, "Cultural Health Attributions, Beliefs, and Practices: Effects on Healthcare and Medical Education," The Open Medical Education Journal, Vol. 2, 2009, pp. 64-74.

[9] A. Radley, "Making Sense of Illness," Sage Publications, London, 1994.

[10] R. A. Shweder, N. C. Much, M. Mahapatra and L. Park, "The 'Big Three' of Morality (Autonomy, Community, Divinity) and the 'Big Three' Explanations of Suffering," In: A. M. Brandt and P. Rozin, Eds., Morality and Health, Taylor \& Frances/Routledge, Florence, 1997, pp. 119169.

[11] C. Herzlich, "Health and Illness: A Social Psychological Analysis," Academic Press, New York, 1973.

[12] R. C. Mishra, "Family Support and Health Care in a Culturally Changing Village Community in Northern India," Social Science International, Vol. 13, 1997, pp. 10-13.
[13] H. Lambart, "Illness, Inauspiciousness and Modes of Healing in Rajasthan," Contributions to Indian Society, Vol. 31, No. 2, 1997, pp. 253-271. doi:10.1177/006996697031002004

[14] R. C. Mishra, "Health Cognition and Practices," In: A. Shukla, Ed., Culture Cognition and Behaviour, Concept, New Delhi, 2009, pp. 264-276.

[15] H. H. Kelley and J. L. Michela, "Attribution Theory and Research," Annual Review of Psychology, Vol. 31, No. 1, 1980, pp. 451-501. doi:10.1146/annurev.ps.31.020180.002325

[16] T. E. Oxman and J. G. Hull, "Social Support, Depression and Activities of Daily Living in Older Heart Surgery Patients," Journal of Gerontology \& Psychosocial Sciences, Vol. 52, No. 1, 1997, pp. 1-14. doi:10.1093/geronb/52B.1.P1

[17] T. A. Glass and G. L. Maddox, "The Quality and Quantity of Social Support: Stroke Recovery as a Psychosocial Transition," Social Science and Medicine, Vol. 34, No. 11, 1992, pp. 1249-1261. doi:10.1016/0277-9536(92)90317-J

[18] D. C. Greenwood, K. R. Muir, C. S. Packham and R. J. Madeley, "Coronary Heart Disease: A Review of the Role of Psychosocial Stress and Social Support," Journal of Public Health Medicine, Vol. 18, No. 2, 1996, pp. 221231. doi:10.1093/oxfordjournals.pubmed.a024483

[19] K. Ell, R. Nishimoto, L. Mediansky, J. Mantell and M. Hamovitch, "Social Relations, Social Support and Survival among Patients with Cancer," Journal of Psychosomatic Research, Vol. 36, No. 6, 1992, pp. 531-541. doi:10.1016/0022-3999(92)90038-4

[20] G. Elal and M. Krespi, "Life Events, Social Support and Depression in Hemodialysis Patients," Journal of Community and Applied Social Psychology, Vol. 9, No. 1, 1999, pp. 23-33. doi:10.1002/(SICI)1099-1298(199901/02)9:1<23::AID-C ASP494>3.0.CO;2-N

[21] A. Scott and G. C. Wenger, "Género y Redes de Apoyo Social en la Vejez [Gender and Social Support in the Elderly]," In: S. Arber and J. Grin, Eds., Relaci_on Entre Género y Envejecimiento [Relationship between Gender and Elderly], Enfoque Sociologico [Sociological Focus]. Narcea, Madrid, 1996.

[22] N. Lin and W. M. Ensel, "Life Stress and Health: Stressors and Resources," American Sociological Review, Vol. 54, No. 3, 1989, pp. 382-399. doi:10.2307/2095612

[23] M. J. Cava and G. Musitu, "Bienestar Psicosocial en Ancianoinstitucionalizadosy No Institucionalizados [Psychosocial Well-Being in Institutionalized and Non-Institutionalized Elders]," Revista Multidisciplinar de Gerontologiá, Vol. 10, 2000, pp. 215-221.

[24] R. O. Hanson and B. N. Carpenter, "Relationships in Old Age: Coping with Challenge Transition," Guilford, New York, 1994.

[25] M. West, W. J. Livesey, L. Reiffer and A. Sheldon, "The Place of Attachment in the Life Events Model of Stress and Illness," Canadian Journal of Psychiatry, Vol. 31, 1986, pp. 202-207.

[26] H. M. Lefcourt, R. A. Martin and W. E. Saleh, "Locus of 
Control and Social Support: Interactive Moderators of Stress," Journal of Personality and Social Psychology, Vol. 47, No. 2, 1984, pp. 378-389. doi:10.1037/0022-3514.47.2.378

[27] I. N. Sandler and B. Lakey, "Locus of Control as a Stress Moderator: The Role of Control Perceptions and Social Support," American Journal of Community Psychology, Vol. 10, No. 1, 1982, pp. 65-80. doi:10.1007/BF00903305

[28] J. Brown and R. Fitzpatrick, "Factors Influencing Compliance with Dietary Restrictions in Dialysis Patients," Journal of Psychosomatic Research, Vol. 32, No. 2, 1988, pp. 191-196. doi:10.1016/0022-3999(88)90054-2

[29] N. M. Kamel, Y. A. Badaway, N. A. El-Zeiny and I. A. Merdan, "Diabetics' Knowledge of the Disease and Their Management Behaviour," East Mediterranean Health Journal, Vol. 5, 2000, pp. 974-983.

[30] K. I. Vanderzee, B. P. Buunk and R. Sanderman, "Social Support, Locus of Control and Psychological Wellbeing," Journal of Applied Social Psychology, Vol. 27, No. 20, 1997, pp. 1842-1859. doi:10.1111/j.1559-1816.1997.tb01628.x

[31] I. G. Sarason, B. R. Sarason and G. R. Pierce, "Social Support: The Search for Theory," Journal of Social and Clinical Psychology, Vol. 9, No. 1, 1990, pp. 133-147. doi:10.1521/jscp.1990.9.1.133

[32] V. S. Helgeson, "Two Important Distinctions in Social Support: Kind of Support and Perceived versus Received," Journal of Applied Social Psychology, Vol. 23, No. 10, 1993, pp. 825-845. doi:10.1111/j.1559-1816.1993.tb01008.x

[33] R. Moos-Morris, K. J. Petrie and J. Weinman, "Functioning in Chronic Fatigue Syndrome: Do Illness Perceptions Play a Regulatory Role?" British Journal of Health Psychology, Vol. 1, No. 1, 1996, pp. 15-25. doi:10.1111/j.2044-8287.1996.tb00488.x

[34] O. S. Dalgard, S. Bjork and K. Tambs, "Social Support, Negative Life Events and Mental Health," The British Journal of Psychiatry, Vol. 166, No. 1, 1995, pp. 29-34. doi:10.1192/bjp.166.1.29

[35] L. Grassi, P. Malacarne, A. Maestri and E. Ramelli, "Depression, Psychosocial Variables and Occurrence of Life Events among Patients with Cancer," Journal of Affective Disorders, Vol. 44, No. 1, 1997, pp. 21-30. doi:10.1016/S0165-0327(97)01445-6

[36] A. K. Dalal and N. Pande, "Psychological Recovery of Accident Victims with Temporary and Permanent Disability," International Journal of Psychology, Vol. 23, No. 1-6, 1988, pp. 25-40. doi:10.1080/00207598808247750

[37] A. K. Dalal and A. K. Singh, "Causal Beliefs and Recovery from Surgery," Psychology and Health, Vol. 6, No. 3, 1992, pp. 193-203. doi:10.1080/08870449208403183

[38] M. Agarwal and A. K. Dalal, "Causal Beliefs and Psychological Recovery of Myocardial Infarction Patients," Journal of Social Psychology, Vol. 133, No. 3, 1993, pp. 385-394. doi:10.1080/00224545.1993.9712157

[39] R. C. Mishra, P. Awasthi and S. K. Singh, "Illness Causation Beliefs and Perceived Illness Consequences in Dia- betic Women," Psychological Studies, Vol. 4, 2004, pp. 238-244.

[40] P. Awasthi, R. C. Mishra and U. P. Shahi, "Health Beliefs and Behaviour of Cervix Cancer Patients," Psychology and Developing Societies, Vol. 18, No. 1, 2006, pp. 37-58. doi:10.1177/097133360501800103

[41] P. Awasthi and R. C. Mishra, "Role of Coping Strategies and Social Support in Perceived Illness Consequences and Controllability among Diabetic Women," Psychology and Developing Societies, Vol. 19, No. 2, 2007, pp. 179 197. doi:10.1177/097133360701900203

[42] M. Arora and R. Kumar, "The Development of a Measure of Social Support," Indian Journal of Psychometry and Education, Vol. 2, 1998, pp. 89-93.

[43] S. Cohen, B. H. Gottlieb and L. G. Underwood, "Social Relationships and Health," In: S. Cohen, L. Underwood and B. H. Gottlieb, Eds., Social Support Measurement and Intervention: A Guide for Health and Social Scientists, Oxford University Press, New York, 2000, pp. 3-25.

[44] J. S. House, K. R. Landis and D. Umberson, "Social Relationships and Health," Science, Vol. 241, No. 4865, 1988, pp. 540-545. doi:10.1126/science.3399889

[45] J. B. Jemmott III and S. E. Locke, "Psychosocial Factors, Immunology Mediation and Human Susceptibility to Infectious Diseases: How Much do We Know?," Psychological Bulletin, Vol. 95, No. 1, 1984, pp. 78-108. doi:10.1037/0033-2909.95.1.78

[46] L. L. Northouse, "Social Support in Patients' and Husbands' Adjustment to Breast Cancer," Nursing Research, Vol. 37, No. 2, 1988, pp. 91-95. doi:10.1097/00006199-198803000-00008

[47] R. Zemore and L. F. Shepel, "Effects of Breast Cancer and Mastectomy on Emotional Support and Adjustment," Social Science and Medicine, Vol. 28, No. 1, 1989, pp. 19-27. doi:10.1016/0277-9536(89)90302-X

[48] J. Primomo, B. C. Yates and N. F. Woods, "Social Support for Women during Chronic Illness: The Relationship among Sources and Types of Adjustment," Research in Nursing and Health, Vol. 13, No. 3, 1990, pp. 153-161. doi:10.1002/nur.4770130304

[49] M. C. Mckenna, M. A. Zevon, B. Corn and J. Rounds, "Psychosocial Factors and the Development of Breast Cancer: A Meta-Analysis," Health Psychology, Vol. 18, No. 5, 1999, pp. 520-531. doi:10.1037/0278-6133.18.5.520

[50] N. K. Janz and M. H. Becker, "The Health Belief Model: A Decade Later," Health Education Quarterly, Vol. 11, No. 1, 1984, pp. 1-47. doi:10.1177/109019818401100101

[51] B. S. Wallston and K. A. Wallston, "Locus of Control and Health: A Review of the Literature," Health Education Monographs, Vol. 6, No. 1, 1978, pp. 107-117. doi: $10.1177 / 109019817800600102$

[52] K. A. Wallston and B. S. Wallston, "Health Locus of Control Scales," In: H. Lefrout, Ed., Research with the Locus of Control Construct Vol. I, Academic Press, New York, 1981.

[53] M. Seeman and T. E. Seeman, "Health Behaviour and Personal Autonomy: A Longitudinal Study of the Sense 
of Control in Illness," Journal of Health and Social Behaviour, Vol. 24, No. 2, 1983, pp. 114-160.

doi: $10.2307 / 2136641$

[54] R. S. Lazarus, "The Costs and Benefits of Denial," In: S. Bresnitz, Ed., Denial of Stress, International Universities Press, New York, 1983.

[55] S. E. Taylor, R. R. Lichtman and J. V. Wood, "Attributions, Beliefs about Control, and Adjustment to Breast Cancer," Journal of Personality and Social Psychology, Vol. 46, No. 3, 1984, pp. 489-502. doi:10.1037/0022-3514.46.3.489

[56] S. E. Taylor, "On Healthy Illusions," Daedalus, Vol. 1, No. 1, 2005, pp. 133-135. doi:10.1162/0011526053124442

[57] M. F. Scheier and C. S. Carver, "On the Power of Positive Thinking: The Benefits of Being Optimistic," Current Directions in Psychological Science, Vol. 2, 1993, pp. 26-30. doi:10.1111/1467-8721.ep10770572

[58] S. Laird, "A Preliminary Investigation into Prayer as a Coping Technique for Adult Patients with Arthritis," Unpublished Doctoral Dissertation, University of Kansas, Lawrence, 1992.

[59] G. Affleck and H. Tennen, "Construing Benefits from Adversity: Adaptotional Significance and Dispositional Underpinnings," Journal of Personality, Vol. 64, No. 4, 1996, pp. 899-922. doi:10.1111/j.1467-6494.1996.tb00948.x

[60] H. Tennen and G. Affleck, "Finding Benefits in Adversity," In: C. R. Snyder, Ed., Coping: The Psychology of What Works, Oxford Press, New York, 1999, pp. 279-
304.

[61] T. R. Elliot and M. Kurylo, "Hope over Acquired Disability: Lessons of a Young Woman's Triumph,” In: C. R. Snyder, Ed., Handbook of Hope: Theory, Measures, and applications, Academic Press, San Diago, 2000, pp. 373-386. doi:10.1016/B978-012654050-5/50022-1

[62] C. R. Snyder, C. J. Berg, J. T. Woodward, A. Gum, K. L. Rand, K. K. Wrobleski, et al., "Hope against the Cold: Individual Differences in Trait Hope and Acute Pain Tolerance on the Cold Pressure Task," Journal of Personality, Vol. 73, No. 2, 2005, pp. 287-312. doi:10.1111/j.1467-6494.2005.00318.x

[63] S. Radhakrishan, "The Hindu View of Life," Blakie, Bombay, 1926.

[64] A. K. Dalal, "Living with a Chronic Disease: Healing and Psychological Adjustment in Indian Society," Psychology and Developing Societies, Vol. 12, No. 1, 2000, pp. 67-81. doi:10.1177/097133360001200105

[65] B. G. Gokhale, "Indian Thought throughout the Ages: A Study of Some Dominant Concepts," Asia Publishing House, Bombay, 1961.

[66] A. C. Paranjpe, "The Nature of Suffering and Its Remedy: A Perspective from the Cultural Tradition of India," Unpublished Manuscript, Simon Fraser University, Burnaby, 1987.

[67] R. A. Shweder, "The Cultural Psychology of Suffering: The Many Meanings of Health in Orissa, India (and Elsewhere)," Ethos, Vol. 36, No. 1, 2008, pp. 60-77. doi:10.1111/j.1548-1352.2008.00004.x 